\title{
GUERRA FISCAL, DESENVOLVIMENTO DESIGUAL E RELAÇÕES FEDERATIVAS NO BRASIL
}

\author{
Otávio Soares Dulci \\ Universidade Federal de Minas Gerais
}

\begin{abstract}
RESUMO
As disputas fiscais entre os estados brasileiros foram um dos traços marcantes da segunda metade da década de 90 no país. O artigo analisa a chamada "guerra fiscal" e seu impacto sobre as relações federativas, procurando identificar o conjunto de fatores que a propiciaram. Explora ainda sua relação com o problema do desenvolvimento desigual das diversas regiões do país. Para ilustrar a generalização dos conflitos interestaduais em matéria fiscal, o trabalho examina algumas frentes da guerra, como a indústria automotiva, o setor de informática e a agroindústria. Por fim, aborda sinteticamente as perspectivas de encaminhamento do problema, tendo em vista a recomposição do pacto federativo em bases mais equânimes e construtivas.

PALAVRAS-CHAVE: guerra fiscal; relações federativas; desenvolvimento regional; Imposto sobre Circulação de Mercadorias e Serviços (ICMS); sistema tributário.
\end{abstract}

\section{INTRODUÇÃO}

Uma das questões em pauta no atual cenário político brasileiro é a chamada guerra fiscal. Tratase de um jogo de ações e reações travado entre governos estaduais (e adicionalmente entre governos municipais) com o intuito de atrair investimentos privados ou de retê-los em seus territórios.

Esse tipo de competição assumiu forma particularmente intensa ao longo dos anos 90 , mas não deve ser visto como algo novo ou surpreendente. Ao contrário, o uso de instrumentos fiscais no repertório de políticas de desenvolvimento regional é bastante antigo no Brasil, assim como em outras nações igualmente marcadas por forte heterogeneidade econômica interna. O que é novo e polêmico, no caso brasileiro, é o cenário por assim dizer hobbesiano, em que a competição passou a ser travada, à falta de meios de regulação capazes de atenuar seu impacto negativo sobre as relações federativas.

Convém, primeiro, chamar a atenção para a expressão "guerra fiscal". Ela já se tornou de uso corrente, pois o fenômeno que designa tem adquirido certo tom corriqueiro. Mas a idéia de "guerra", utilizada para descrever relações entre unidades de uma federação, é tudo menos trivial. É uma metáfora muito significativa, que traduz um problema de cunho eminentemente constitucional, no sentido pleno do termo, ou seja, quanto ao grau de consenso sobre os fundamentos da ordem política.

\section{O FEDERALISMO BRASILEIRO}

Nossa organização é federativa - assim estipula a Constituição como cláusula pétrea. E não por acaso. Essa definição está de acordo com o processo formativo do Brasil como nação - processo que tem a ver com a articulação das partes do território em um conjunto razoavelmente coeso, o que, em virtude das características peculiares do país (geográficas, históricas, culturais e políticas), sempre representou e continua a representar um grande desafio: construir a unidade na diversidade.

O sistema federal é o mecanismo adequado para garantir a união nesse contexto. Em teoria, creio que não há grande divergência sobre isso. Parece clara a autenticidade do ideal federativo no Brasil desde seus primórdios. As raízes do sistema constituíram-se ainda na fase colonial, quando a vida política brasileira já continha, em embrião, o caráter dual de uma ordem federativa, distinguindo-se claramente o poder central (as autoridades da Coroa) e o poder local (as câmaras municipais).

Mas a prática mostra outra coisa. A história do federalismo brasileiro tem sido bastante movi- 
mentada, indicando a dificuldade de equilibrar as partes e o todo de modo eficiente e duradouro.

Formalmente, o Brasil tornou-se uma federação de estados após a proclamação da República. No entanto, a instabilidade que caracterizou as nossas instituições políticas ao longo do tempo tem feito essa caracterização formal perder muito de seu significado. De fato, a idéia de "construção do pacto federativo" é rigorosamente aplicável ao Brasil, pois temos uma ordem federativa instável, incompleta, que se constrói em face de grandes obstáculos e fatores de desconstrução.

Podemos consolar-nos com a constatação de que a estabilidade não é um atributo forte do modelo federativo, a julgar pela experiência dos países que o adotam. Ele possui grandes vantagens, mas é vulnerável a muitos obstáculos e fatores de transformação. $\mathrm{O}$ exemplo do Canadá indica a dificuldade de garantir uma união estável, mesmo em contextos de prosperidade econômica e altos índices de bem-estar social.

Em face dessas considerações, como abordar a questão da guerra fiscal? Ela é indício, entre nós, desta instabilidade mais ou menos comum aos estados federais. Seria uma das formas pelas quais a dificuldade de compor interesses regionais manifesta-se no Brasil, já que não temos divisões lingüísticas, religiosas ou étnicas de base territorial a ameaçar a unidade. O nosso problema maior é o desequilíbrio econômico (com suas implicações sociais e políticas) entre as regiões. Sem falar, naturalmente, da tendência centrípeta recorrente na política brasileira, uma espécie de unitarismo disfarçado que ignora as diferenças em nome de interesses que se apresentam como gerais.

\section{A GUERRA FISCAL E SUAS CONDIÇÕES RECENTES}

O conflito fiscal entre os estados, em seu formato contemporâneo, tem causas bem definidas. É o efeito de certas condições políticas e econômicas que emergiram, uma após outra, desde meados da década de 80 , cuja interação resultou potencialmente crítica.

Houve, em primeiro lugar, o processo de desmontagem do regime autoritário de 1964, culminando com a Constituição de 1988. Entre os elementos da referida desmontagem ocupava lugar de destaque um impulso muito claro de descentralização política e institucional, a traduzir-se em deslocamento de poder em favor de estados e municípios. É inegável o sentido democrático da descentralização estabelecida na Carta de 1988; porém, ela estimulou uma espécie de anomia no que diz respeito ao quadro tributário no âmbito da federação, ao atribuir a cada estado o poder de fixar autonomamente as alíquotas do Imposto sobre Circulação de Mercadorias e Serviços (ICMS) - o imposto que constitui a base da receita estadual. Estava preparado o alicerce jurídico para as escaramuças da guerra físcal.

A revisão do pacto federativo promovida pela Constituição de 1988 provocou uma atitude hostil da União em face da descentralização, pelo que ela significava de perda de receita. Desde então observa-se o empenho do governo federal em ampliar seu quinhão do bolo tributário, empregando para isso vários meios, inclusive alguns que apontam para uma nova centralização, colidindo portanto com a linha consagrada pela Constituição vigente.

Ao mesmo tempo, o governo da União tem levado adiante, desde o início da década de 90, toda uma seqüência de medidas de orientação liberal, que se ligam ao cenário da guerra fiscal sob dois aspectos. Um deles diz respeito ao abandono de políticas e de instrumentos de coordenação interregional, dentro da estratégia mais ampla de mudança do papel diretivo do poder central sobre a economia. As agências federais de desenvolvimento regional, há muito esvaziadas, foram finalmente extintas em 2001. Tal setor da ação governamental foi, esse sim, descentralizado de bom grado, deixado praticamente a cargo das administrações subnacionais. Além do mais, consolidou-se no âmbito do governo federal uma "postura basicamente avessa a políticas industriais ativas, de caráter discricionário. Seu discurso tem enfatizado sempre que as políticas relevantes são aquelas voltadas para os ganhos sistêmicos, para a redução do 'custo Brasil' etc. Na prática, a progressiva retirada do governo federal das ações discricionárias não levou à 'saudável hegemonia do mercado', como muitos esperavam, mas criou um vazio de políticas rapidamente preenchido pela ação dos grupos regionais" (PRADO \& CAVALCANTI, 2000, p. 113).

Assim o terreno ficou livre para as disputas entre os estados por oportunidades e meios de desenvolvimento, a serem procurados cada um por si. Configurava-se o arcabouço político para as ações e reações desordenadas da guerra fiscal. 
$\mathrm{O}$ outro aspecto refere-se à abertura da economia brasileira, com o aprofundamento de sua inserção global. A abertura ensejou a condição econômica para a escalada da guerra fiscal, na medida em que atraiu um fluxo crescente de capitais internacionais em busca de oportunidades de investimento no país. Parcela relevante da guerra fiscal tem a ver com a disputa por projetos industriais de origem externa, sendo os mais visíveis os da indústria automobilística.

Por certo, a gradual consolidação do Mercosul, junto com o quadro de relativa estabilidade proporcionado pelo Plano Real, ofereceram boas perspectivas para as corporações multinacionais incluírem o Brasil em seus planos de expansão. Considera-se, em geral, que o leilão de incentivos fiscais promovido pelos governos estaduais não tem sido importante para que essas grandes empresas definam-se por novos projetos no Brasil. Elas o fariam de qualquer maneira pelas razões de mercado. E instalar-se-iam em princípio na área economicamente central do país. Ora, é precisamente essa opção que o leilão de incentivos pretende alterar. Trata-se de cobrir com vantagens financeiras o custo da alocação de uma empresa em outra parte que não aquela que ela escolheria por uma lógica de mercado.

Portanto, a guerra fiscal é fomentada pela internacionalização, na medida em que a disputa por capitais externos obriga a crescentes concessões dos estados. Na origem estão as desigualdades regionais do país e a limitação de recursos internos para investimentos capazes de atenuar tais desigualdades. Tendo isso em conta, pode ser oportuno para cada estado, considerado isoladamente, entrar nesse jogo, sobretudo se suas chances de atrair investimentos sem incentivos são diminutas. Criam-se novos empregos, diversifica-se a produção local, as indústrias incentivadas atraem outras que são suas fornecedoras, o que por sua vez expande o nível de emprego e a renda da região.

Para o país como um todo, contudo, as conseqüências são negativas. Ao lado das tensões políticas entre os estados, cabe ponderar qual o impacto social das renúncias fiscais, promovidas por governos estaduais que nem sempre estão em condições de fazê-lo sem sacrificar ainda mais suas populações. Como adverte Diniz, a guerra fiscal corrói as finanças públicas, compromete receitas futuras e desvia os preços relativos. "Nessa guerra, ganham os estados mais desenvolvidos, com melhores condições locacionais e maior cacife financeiro e político. Isto seguramente agravará as desigualdades regionais" (DINIZ, 2000, p. 343).

Os efeitos sobre o cenário empresarial também são consideráveis. As principais vencedoras da guerra fiscal são as empresas multinacionais, às quais se destinam os maiores incentivos. As grandes empresas nacionais arranjam-se, pelo volume de vendas internas, mas perdem relativamente se não receberem incentivos. Já os micro e pequenos empresários perdem em competitividade de seus concorrentes dos estados que adotam esquemas de incentivo. Estabelecese uma situação de franca desigualdade: enquanto algumas empresas poderosas são beneficiadas, as demais são oneradas com a carga normal de impostos, que tendem a considerar muito alta (porque mal distribuída), queixando-se ainda dos governos por um tratamento que identifica inadimplência com sonegação. Nesse sentido, não surpreende o avanço da economia informal, que corresponde a fatia substancial das atividades econômicas no Brasil.

\section{DESIGUALDADES REGIONAIS E MODE- LOS DE DESENVOLVIMENTO}

Ao lado dos fatores apontados, que permitem entender a gravidade do quadro recente, convém dar atenção a fontes mais remotas das disputas entre os estados. Sob esse ângulo, a raiz das operações de guerra fiscal encontra-se no processo de desenvolvimento desigual, ou melhor, em estratégias de recuperação econômica adotadas por unidades importantes da federação para enfrentar o seu atraso relativo.

A industrialização do Brasil tomou corpo a partir dos anos 30, com a interligação de mercados regionais até então bastante isolados uns dos outros em um mercado nacional protegido da concorrência externa. Deu-se um processo de concentração industrial que abafou aos poucos o parque industrial preexistente em diversas partes do país. Estabeleceu-se, com isso, um esquema de divisão interregional do trabalho centralizado no eixo Rio-São Paulo, mas que se inclinou cada vez mais para São Paulo. É sabido que a primazia paulista derivou de condições excepcionais de crescimento ligadas ao "complexo cafeeiro" (CANO, 1990). Aprofundou-se pela dinâmica de aglomeração do mercado, mas contando também com um fator extra-mer- 
cado: a política cambial do Brasil, que, para controlar as importações, protegeu fortemente o setor industrial já implantado. Isso incrementou ainda mais a centralidade da economia de São Paulo em face das outras áreas menos desenvolvidas.

O processo aproxima-se da situação descrita pelo modelo de centro-periferia, mas, no quadro brasileiro, altamente heterogêneo, seria errôneo identificar áreas muito diversas sob o rótulo indistinto de "periferia". Há diferenças relevantes - entre grandes regiões, entre estados e até dentro de cada estado - quanto ao grau de desenvolvimento (ou de atraso relativo), quanto ao potencial produtivo e quanto às condições políticas para aproveitar esse potencial. Considerar tais diferenças é fundamental para uma apreciação adequada de como o processo de desenvolvimento desigual levou a esforços de recuperação econômica por meio de mecanismos institucionais, notadamente na área fiscal.

Retomando uma tipologia elaborada em trabalho anterior (DULCI, 1999), distinguem-se na cena histórica brasileira quatro vias de desenvolvimento regional. Uma é a que corresponde à experiência paulista, baseada em fatores de mercado. Uma segunda é a de regiões que se dinamizaram como um desdobramento da economia paulista. O impulso foi também dado pelo mercado, mas de fora para dentro. Casos típicos são os do Paraná e de Goiás, mais recentemente o do Mato Grosso do Sul, sem contar algumas áreas de Minas Gerais adjacentes a São Paulo (o sul de Minas e o Triângulo Mineiro).

No outro extremo, temos o Nordeste e a Amazônia, vasta porção do território brasileiro situada em posição nitidamente periférica - em relação ao eixo industrial do Sudeste - e portanto com baixo potencial de crescimento segundo a lógica do mercado. Nesse caso, para recuperar seu atraso, seriam necessárias iniciativas no campo políticoinstitucional. E essas viriam de fora, do governo federal, movido por motivos estratégicos de cunho nacional. Assim, ambas foram definidas como "regiões-plano", alvo de benefícios fiscais e de outros tipos de apoio, com a criação da SUDENE (Superintendência de Desenvolvimento do Nordeste) e mais tarde da SUDAM (Superintendência de Desenvolvimento da Amazônia).

Tais agências consolidaram uma linha de atuação do governo federal que remontava ao início do século, com a fundação do órgão de combate às secas (o atual Departamento Nacional de Obras de Combate à Seca) e que avançara nos anos 40, quando surgiram a Comissão do Vale do São Francisco e a Superintendência do Plano de Valorização Econômica da Amazônia. O escopo original da SUDENE e da SUDAM era abrangente, mas, com o tempo, elas fixaram-se sobretudo na concessão de incentivos fiscais como meio de viabilizar empreendimentos industriais e agropecuários no Nordeste e na Amazônia. O uso desse instrumento traduzia uma política compensatória, por assim dizer, considerada legítima no marco das relações federativas. De todo modo, não alterava verdadeiramente a distribuição de poder político e econômico no sistema de regiões que é o Brasil.

Temos, por fim, um quarto modelo de desenvolvimento regional, correspondente às áreas da federação que buscaram fórmulas intermediárias no que diz respeito à equação mercado-Estado. Encaixam-se nesse padrão diversos estados do Centro-Sul, como Minas Gerais e o Rio Grande do Sul. Dispondo de certo potencial de expansão econômica, a recuperação do atraso era buscada pelo manejo de recursos políticos e institucionais. $\mathrm{O}$ fator diferencial, porém, era a iniciativa interna do processo - em contraste com o modelo do Nordeste e da Amazônia - pois o menor grau de atraso não justificaria, por si mesmo, ações estratégicas do governo federal. O ponto de interrogação diz respeito às condições (políticas, antes de tudo) para iniciar e levar adiante fórmulas consistentes de desenvolvimento, o que é uma variável importante na análise de cada caso.

Essa via intermediária, que suplementa a dinâmica de mercado com mecanismos institucionais, constitui a fonte por excelência da guerra fiscal. Pois os seus principais protagonistas são os grandes estados do país, relativamente competitivos no que tange à alocação de investimentos. Alguns deles adquiriram uma longa experiência na formulação de políticas desenvolvimentistas, aparelhando-se, para tanto, com instituições públicas de planejamento, de serviços de infraestrutura, de financiamento e de captação de investimentos. O uso de incentivos fiscais, nesse contexto, seria apenas uma das formas de viabilizar suas estratégias de industrialização. No entanto, é a forma mais visível e também a mais controversa.

O manejo de instrumentos fiscais, pelos estados que introduziram estratégias próprias de desenvolvimento, não caracterizou até certo momento 
o que chamamos de guerra fiscal. Uma razão é que a hegemonia alcançada por São Paulo era tão absoluta que dificilmente seria abalada por tais iniciativas. Estas, além disso, adquiriam foros de legitimidade, do ponto de vista do equilíbrio federativo, considerando a importância política de estados como Minas Gerais ou o Rio Grande do Sul no contexto nacional.

Mas o fator principal a inibir as tensões entre os estados foi o papel ativo que o governo federal desempenhou ao longo do tempo, ora mais vigorosamente, ora menos, para abrir oportunidades que compensassem a concentração da economia brasileira. A essa linha de ação atribui-se função relevante para cimentar a unidade nacional nas condições heterogêneas do Brasil, redundando em uma espécie de pacto de soldagem de interesses por meio de acordos e alianças: "Esse 'pacto federativo' foi o mecanismo de compensação construído para que se obtivesse um equilíbrio peculiar entre as unidades territoriais, como parte de um processo de desenvolvimento sustentado pela ação de um governo forte e indutor. O equilíbrio inter-regional brasileiro não pode, portanto, ser visto como efeito, exclusivo ou predominante, da ação de mecanismos e fluxos econômicos gerados a partir de forças do mercado" (SILVA, 1997, p. 352).

O ápice dessa linha de conduta foi o governo Geisel, que adotou uma posição clara em favor da desconcentração industrial, canalizando volumosos projetos estatais para os estados de desenvolvimento intermediário: os pólos petroquímicos da Bahia e do Rio Grande do Sul, a Açominas, as usinas nucleares no Rio de Janeiro etc.

No entanto, dos anos 80 em diante, esse papel do governo central foi esvaziado, e desenhou-se o atual cenário de conflito, pelo entrelaçamento de uma série de fatores já mencionados nesta exposição. O caráter intrincado da questão revelase pelo envolvimento dos grandes estados da federação na disputa por macroprojetos industriais de capital externo - embora ele manifeste-se igualmente por outros focos de controvérsia a respeito de impostos e subsídios públicos, atingindo os mais variados setores da economia. É o que veremos a seguir.

\section{AS ÁREAS DE ATRITO E OS CONTEN- DORES}

Sem pretender uma classificação exaustiva, examino a seguir algumas áreas de atrito que parecem mais significativas para ilustrar a diversidade de setores e de protagonistas da guerra fiscal no Brasil.

\section{V.1. A indústria automotiva}

Foi no setor automobilístico que o manejo de instrumentos fiscais e financeiros pelos estados adquiriu maior visibilidade, numa escalada que marcou a segunda metade da década de 90 .

Em rigor, esse processo teve como antecedente notório a implantação da Fiat em Minas Gerais no começo dos anos 70. Foi a primeira iniciativa relevante de desconcentração da indústria de automóveis para fora de São Paulo. O governo de Minas Gerais concedeu diversos benefícios à montadora italiana, em impostos, infra-estrutura e participação acionária, o que, por sinal, foi altamente vantajoso pelos efeitos multiplicadores do empreendimento. Contudo, esse permaneceu como caso isolado - ou quase, pois alguns anos depois a Volvo se estabeleceu no Paraná - sem prejuízo para as relações entre os estados referidos e para o sistema federativo como um todo. São Paulo continuou a abrigar o grosso da indústria automotiva com todas as vantagens decorrentes, inclusive em arrecadação de impostos.

Relativamente estagnado durante muito tempo, o segmento automotivo entrou em fase de renovação nos anos 90 . Novas montadoras dirigiram sua atenção para o Brasil e as empresas já instaladas no país fizeram planos de expansão para enfrentar a concorrência. Diante disso, vários governos estaduais moveram-se para atrair os investimentos em perspectiva. O resultado desse esforço foi uma redistribuição do parque automotivo brasileiro que contemplava vários estados do Centro-Sul. Desde 1996 entraram em operação unidades de montagem de veículos das seguintes companhias:

Quadro 1 - Unidades da indústria automobilística implantadas no Brasil, 1996-2001

\begin{tabular}{|l|l|}
\hline \multicolumn{1}{|c|}{ Estado } & \multicolumn{1}{c|}{ Empresas automotivas } \\
\hline Bahia & Ford \\
\hline Goiás & Mitsubishi \\
\hline Minas Gerais & $\begin{array}{l}\text { Mercedes Benz (atualmente Daimler- } \\
\text { Chrysler) e Fiat-Iveco }\end{array}$ \\
\hline Paraná & Chrysler, Renault e Audi-Volkswagen \\
\hline Rio de Janeiro & Volkswagen e Peugeot-Citroen \\
\hline Rio Grande do Sul & General Motors e Navistar \\
\hline São Paulo & Honda, Toyota e Land Rover \\
\hline
\end{tabular}

Glauco Arbix elaborou uma interessante análise 
a respeito da escalada das disputas fiscais, identificando quatro momentos sucessivos no processo de expansão dos empreendimentos automobilísticos pelo território brasileiro. O processo iniciou-se com a edição do Novo Regime Automotivo, em 1995. Em um primeiro momento, não obstante o vulto dos incentivos oferecidos, "o nível da disputa [...] mal se diferenciava da prática disseminada pelo país de oferecer incentivos locais para favorecer o deslocamento industrial" (ARBIX, 2002, p. 118).

Uma segunda fase tomou corpo em 1996 com as ofertas do Paraná, que mudaram a qualidade da competição ao envolverem participação direta do Estado no investimento da montadora. O Paraná passou a abrigar em pouco tempo um expressivo pólo automobilístico, com as novas plantas da Volkswagen-Audi, da Renault e da Chrysler.

Como sintoma da intensidade da disputa, ainda em 1996 o Rio Grande do Sul adotou uma terceira modalidade de oferta, cuja principal característica foi o financiamento total do empreendimento. Para a General Motors, o governo estadual transferiu cerca de 250 milhões de dólares na assinatura do contrato, além de financiar parcialmente a instalação dos vinte fornecedores da fábrica.

$\mathrm{O}$ apoio governamental a tais projetos partiu das respectivas administrações estaduais. O governo federal não interferiu na competição que elas travaram: afinal, era um jogo entre as unidades mais prósperas e poderosas do país. Mas não logrou ficar totalmente alheio ao assunto, uma vez que o movimento de expansão do setor extravasou para fora do Centro-Sul. De fato, em virtude do regime especial que a legislação assegurou para projetos automotivos que se instalassem nas regiões menos industrializadas, foi ventilado $\mathrm{o}$ interesse de várias corporações, a maioria asiáticas, em fabricar tratores, motos e outros veículos nos estados do Nordeste, do Norte e do Centro-Oeste. O esquema parecia irrealista, e nada se concretizou, até que sobreveio o episódio da Ford, em 1999.

Essa foi a batalha mais famosa da guerra fiscal e representou um quarto momento, de "canibalização de um estado da federação por outro" (ARBIX, 2002 , p. 119). A Ford havia contratado a localização de uma nova fábrica no Rio Grande do Sul, mas o novo governo gaúcho, empossado em 1999, quis rever os termos da negociação por os considerar demasiado onerosos para o estado ${ }^{1}$. A

\footnotetext{
1 A revisão dos contratos celebrados com montadoras de
} veículos pelo governo Antônio Britto (1995-1998) havia
Ford, de sua parte, não concordou e tentou dobrar os dirigentes gaúchos com a ameaça de transferir o projeto para outra área do país. Antes que o impasse fosse desfeito, o governo da Bahia, agilmente, interpôs-se e deslocou o projeto para seu território, com a oferta de numerosas vantagens, entre as quais se destacavam os incentivos especiais do regime automotivo para o Nordeste.

Para tanto, seria preciso o apoio do governo federal, o qual, após algumas divergências internas, chegou a uma fórmula para viabilizar financeiramente a iniciativa da Bahia. Por essa fórmula, o prazo de adesão ao regime automotivo para o Nordeste, o Norte e o Centro-Oeste, já encerrado em 1998 , foi reaberto por mais um ano para atender à situação específica da Ford. Porém o montante da renúncia de impostos federais ficou bem menor do que previra originalmente o referido regime reduziu-se de $\mathrm{R} \$ 700$ milhões para $\mathrm{R} \$ 180$ milhões anuais em média, até 2010, em montante tido como suficiente para compensar a Ford pelo custo adicional de produzir veículos na Bahia e não no Centro-Sul (INCENTIVO A MONTADORA, 1999, p. 6). Houve também a concessão de crédito pelo BNDES, além obviamente de benefícios oferecidos pelo governo da Bahia.

A batalha em torno da fábrica da Ford pôs em evidência a complexidade dos ingredientes políticos contidos na guerra fiscal. Em primeiro lugar, ela acabou envolvendo o governo federal, que ficou sujeito a escolhas difíceis no processo. Já que vinha adotando uma atitude de não-interferência nas disputas entre os estados, sua melhor opção seria ficar alheio a mais essa. Por vários motivos. A elevada renúncia de impostos pleiteada pela Bahia (com base no regime automotivo original para o Nordeste) viria a enfraquecer o rigor do ajuste fiscal em andamento. Havia também o receio de contrariar, com tais incentivos, as normas do Mercosul e da Organização Mundial do Comércio. Por isso o governo federal negociou de modo a reduzir sua parte no empreendimento, como segunda melhor opção, pois ficar de fora não lhe foi possível, em virtude do poder que os baianos então detinham

sido defendida durante a campanha sucessória em 1998 pelo candidato da oposição, Olívio Dutra, que venceu Britto nas urnas. Depois de assumir o cargo, Dutra conseguiu renegociar o contrato com a General Motors, cuja unidade foi inaugurada em 1999. Situação análoga ocorreu em Minas Gerais à mesma época, quando o novo governador, Itamar Franco, promoveu uma renegociação do contrato com a Mercedes-Benz. 
na política nacional sob o comando de Antônio Carlos Magalhães, Presidente do Senado. Sua pressão foi muito forte, e contou com aliados importantes em todo o Nordeste e mesmo dentro do governo. Assim, a Bahia reuniu apoio suficiente para prevalecer sobre o Rio Grande do Sul - estado que vivia situação diversa, governado por uma aliança de partidos de oposição ao governo federal.

Em segundo lugar, o que parecia apenas uma disputa entre dois estados acabou por envolver vários outros, a indicar o impacto sistêmico da guerra fiscal sobre as relações federativas. $\mathrm{O}$ conflito logo envolveu também São Paulo, pelo receio de que a Ford, uma vez implantada na Bahia, fechasse suas antigas unidades de produção em território paulista. O Governador Mário Covas criticou duramente o arranjo que se articulava na esfera federal para beneficiar a Bahia e preparouse para impugná-lo no Supremo Tribunal (COVAS QUER DERRUBAR, 2000, p. 4). Diante dos protestos de São Paulo, os governadores e outros expoentes dos principais estados nordestinos mobilizaram-se em defesa da iniciativa baiana. Com um discurso marcadamente regionalista, atribuíram a São Paulo o propósito de impedir o desenvolvimento do Nordeste. A reação de São Paulo voltou-se, em seguida, contra outros estados que estariam provocando perdas à economia paulista, entre eles os vizinhos Paraná, Rio de Janeiro e Minas Gerais.

Em terceiro lugar, há a questão dos resultados obtidos com o investimento. O benefício da refrega em torno da Ford parece expressivo para a Bahia. Além dos empregos, da renda e do fluxo comercial gerados diretamente pela montadora, deve-se contabilizar seus frutos indiretos. Por exemplo, a revitalização do decadente parque metalúrgico baiano, formado na época dos grandes projetos do setor petrolífero e petroquímico. A renúncia fiscal assumida pelo estado é considerável, mas não chega a desequilibrar suas contas, uma vez que a Bahia encontra-se em situação favorável nesse terreno.

Para o Rio Grande do Sul, ao contrário, a modalidade de incentivo por pagamento antecipado excedia a capacidade financeira de seu governo, daí a controvérsia que redundou na desistência da Ford. O governo de Minas Gerais, por sua vez, renegociou o contrato original com a Mercedes Benz, para adequá-lo às crescentes limitações do erário estadual. Além disso, teve ainda que conviver com a hipótese do encerramento da produção da empresa, cujas vendas ficaram muito abaixo do esperado. $\mathrm{O}$ que foi hipótese em Minas Gerais converteu-se em realidade no Paraná, onde a Chrysler optou por desativar sua fábrica e devolver os incentivos recebidos do governo. Esse último fato chama a atenção para a insuficiência do instrumento fiscal como esteio de políticas de desenvolvimento regional num cenário global de grande mobilidade de capitais.

\section{V.2. São Paulo e a guerra fiscal: as indústrias de alta tecnologia}

Uma das principais mudanças em curso tem a ver com a situação de São Paulo, cujo vasto parque industrial passou a enfrentar desafios com a internacionalização, exigindo maior esforço de competição com outras áreas. Embora a condição de centro financeiro do país assegure-lhe firme hegemonia, o governo paulista mostrou-se bastante ativo diante da guerra fiscal, sobretudo após o caso da Ford. Primeiro, adotando a prática de reagir a medidas de outros estados por meio de recursos judiciais ao Supremo Tribunal Federal. Em segundo lugar, introduzindo medidas de cunho fiscal para proteger o seu sistema produtivo.

A iniciativa mais notória nesse sentido foi uma lei estadual de julho de 1999 que reduzia substancialmente a alíquota do ICMS para as empresas paulistas credenciadas no Simples (programa de benefícios fiscais para micro e pequenas empresas), desde que fizessem no mínimo $80 \%$ de suas compras dentro do estado de São Paulo. Para as microempresas a alíquota seria zero, para as pequenas cairia de $18 \%$ para $1 \%$ - uma medida protecionista de tipo clássico, voltada para a substituição de importações. O governo justificou a lei em nome do incentivo à produção e da geração de empregos. Enfrentou, contudo, forte reação, e não só de governos e entidades empresariais de outros estados. Segmentos empresariais de São Paulo, como a Federação das Câmaras de Dirigentes Lojistas, consideraram-se prejudicados, o que surpreendeu o governador Mário Covas e fê-lo abandonar a iniciativa um mês depois. A pressão mais forte veio de Minas, mas também de outros estados (Rio de Janeiro, Paraná, Santa Catarina, Espírito Santo, Bahia, Rio Grande do Sul), todos dispostos a questionar a constitucionalidade da lei paulista junto ao STF (COVAS DECIDE REVOGAR, 1999, p. 3; MINAS VAI AO SUPREMO, 1999, p. 5). 
No segmento automobilístico a atratividade de São Paulo decaiu devido às deseconomias da aglomeração na capital e no ABC, o que significa que os incentivos fiscais de outros estados só explicam parte do movimento de desconcentração observado nos anos 90. Contudo, nos setores industriais de ponta a liderança de São Paulo foi reafirmada em vitórias recentes.

Uma delas, em junho de 2000, foi a preservação em território paulista de todo o parque aeronáutico da Embraer. Esta empresa, ao planejar a construção de uma nova fábrica, despertou o interesse de Minas Gerais e do Paraná. Os mineiros tencionavam atrair o projeto para o Triângulo Mineiro (Uberlândia ou Uberaba) e ofereceram uma contrapartida de R \$25 milhões em infra-estrutura, além do acesso aos fundos estaduais de atração industrial. Uma oferta realista, por sinal, longe dos compromissos temerários que assinalaram a década de 90. Dada a natureza da indústria aeronáutica, parte substancial do investimento referia-se ao financiamento de pesquisas, e quanto a isso a ampla superioridade de São Paulo evidenciou-se pelos termos do acordo afinal celebrado: $\mathrm{R} \$ 27,7$ milhões para infra-estrutura e R $\$ 109,2$ milhões da Fundação de Amparo à Pesquisa do Estado de São Paulo, a FAPESP, para financiamento de pesquisas. $O$ investimento da Embraer foi previsto em $\mathrm{R} \$ 210$ milhões, sendo R $\$ 60$ milhões para pesquisas (SÃO PAULO INVESTIRÁ, 2000).

Outra vitória de São Paulo foi a aprovação da nova Lei de Informática, sancionada em janeiro de 2001. A discussão no Senado deu-se em torno de benefícios fiscais, ou melhor, em torno de modelos de incentivo - um antigo e um moderno - que possuíam implicações regionais distintas. No núcleo da disputa defrontaram-se os estados de São Paulo e do Amazonas, mas ela atingia pretensões de outras unidades, como a Bahia.

$\mathrm{O}$ interesse do Amazonas era manter o status diferenciado da Zona Franca de Manaus, que garantia às suas empresas a isenção de $88 \%$ do imposto de importação de componentes. Ora, o projeto de lei em pauta, já aprovada na Câmara dos Deputados, incluía telefones celulares e monitores de vídeo entre os bens de informática, o que significava retirar o incentivo à importação para a montagem de tais produtos em Manaus. O sentido do projeto era precisamente o de internalizar a cadeia produtiva do setor. E atendia bem ao interesse de São Paulo, que argumentava em favor da isonomia nas condições de investimento entre os estados. Em condições de equivalência fiscal, São Paulo esperava abrigar a maior parte dos novos projetos (BRIGA POR INCENTIVOS, 2000, p. A-9).

Por iniciativa de senadores do Nordeste, articulou-se um acordo em torno da meta de obter certo equilíbrio na distribuição de incentivos entre os estados. Conforme a emenda aprovada, um estado ficaria impedido de aprovar novos projetos se, nos dois anos anteriores, tivesse recebido mais da metade do total de incentivos previstos na lei. Seria um meio de dificultar a concentração das indústrias de informática e automação em São Paulo. No entanto, esse artigo foi vetado pelo Presidente Fernando Henrique Cardoso ao sancionar a lei. $\mathrm{O}$ veto correspondeu ao empenho conjunto do Ministério do Desenvolvimento e do governo de São Paulo, atendendo aos interesses da indústria do Sudeste representados pela ABINEE (Associação Brasileira da Indústria Eletroeletrônica) (LEI DE INFORMÁTICA ATRAI, 2001, p. A-9).

A opção nesse caso foi por um modelo novo de incentivo, em detrimento do antigo esquema que tem sustentado por muito tempo as atividades da Zona Franca de Manaus. Nela surgiu um parque industrial baseado exclusivamente em incentivos fiscais. Ora, em segmentos como a informática e a eletrônica os fatores ligados a pesquisa e a desenvolvimento tecnológico são cruciais para o êxito dos empreendimentos. A existência de base acadêmica forte e de centros de produção de conhecimento, amparados por sistemas de fomento, define para as indústrias de alta tecnologia suas localizações naturais, por assim dizer, em contraste com fórmulas de alocação artificiais, incapazes de assegurar trajetórias sustentáveis a longo prazo.

A Zona Franca de Manaus, nesse sentido, constitui uma localização artificial para a indústria de alta tecnologia, mera linha de montagem sustentada por favores fiscais. Mas não é caso isolado. No debate da Lei da Informática a oposição do Amazonas a São Paulo foi secundada pela Bahia, e não por acaso. Há algum tempo o governo da Bahia dedica-se a criar um pólo de informática em Ilhéus por um caminho semelhante. É sabido que o eixo Ilhéus-Itabuna foi gravemente afetado pela decadência da produção e exportação do cacau, de grande significação para a economia baiana. Como alternativa vislumbrou-se uma estratégia 
de industrialização acelerada por meio de largos subsídios e vantagens fiscais, além de atrativos como o baixo custo da mão-de-obra. Assim se instalaram indústrias de bens de consumo, como a Azaléia (calçados) em Itabuna. No tocante ao pólo de informática de Ilhéus, o caráter artificial do processo é ainda mais nítido. Em 1999, conforme constatou Diniz, havia 16 empresas do ramo, mas sem nenhuma integração local, caracterizando-se como simples montadoras. Não há sequer escola de engenharia na região, o que seria um pré-requisito básico para a consolidação do pólo. (DINIZ, 2000, p. 343). O modelo de canibalização foi também adotado nesse caso. Empresas de outros estados foram para Ilhéus atraídas por ofertas imbatíveis de incentivos, abandonando seus locais de origem. Esse fluxo afetou particularmente o vale do Sapucaí - apelidado de "Vale da Eletrônica" - no sul de Minas, que é uma das áreas importantes de desenvolvimento da indústria eletroeletrônica nacional.

\section{V.3. Agroindústria: uma visão a partir de Minas Gerais}

Uma frente menos famosa da guerra fiscal, mas nem por isso menos danosa, é a da agroindústria, observando-se igualmente alguns embates relativos à agricultura enquanto tal. Nesse terreno o número de estados em competição é bem maior do que nos setores industriais examinados até aqui. Em regra o alvo são empresas já instaladas, às vezes bastante tradicionais, que se dispõem a transferir sua produção para outros estados, atraídas pela perspectiva de carga tributária reduzida ou nula.

Como se trata de um quadro muito vasto, vou abordá-lo por meio do exame das principais controvérsias que emergiram em Minas Gerais, em anos recentes, no que diz respeito à tributação do setor.

O setor de leite e derivados, de longa tradição em Minas, é responsável por mais de $30 \%$ da produção brasileira. Disputas fiscais nessa área não são novas. Houve um longo contencioso com o Rio de Janeiro, nas últimas décadas do século $\mathrm{XX}$, a respeito da tributação do leite exportado por Minas. Ultimamente a questão reacendeu-se, pelo mesmo motivo: o governo de Minas Gerais aplica uma política fiscal conservadora, relutando em abrir mão da arrecadação do setor (que contribui com $2,5 \%$ do ICMS mineiro), em contraste com seus vizinhos, cuja maior liberalidade tem seduzido diversas empresas.

Às vezes esse contraste é usado para pressionar em favor de facilidades fiscais. A Itambé (Cooperativa Central dos Produtores Rurais de Minas Gerais), maior empresa do ramo, tem feito isso com freqüência. Em meados de 2000, por exemplo, anunciou que estudava a transferência de sua produção para Goiás, onde mantém duas fábricas. Alegava que o governo de Minas cobra 7\% de ICMS sobre o leite longa-vida, ao passo que o estado de Goiás oferece isenção de $80 \%$ para o mesmo produto. Estava claro que era um mecanismo de pressão ou blefe, pois a transferência não era praticável. O que a empresa reivindicava era um tratamento fiscal idêntico ao de Goiás.

Outras vezes, porém, as ameaças concretizaram-se. Na mesma época a Parmalat desativou parte de sua fábrica no sul de Minas e transferiu-a para São Paulo, justificando a decisão por motivos fiscais: o ICMS cobrado em Minas para os seus produtos é de $12 \%$, enquanto o de São Paulo é de 7\%. O Presidente da Federação das Indústrias do Estado de Minas Gerais (FIEMG), Stefan Salej, protestou: "a política fiscal do governo mineiro está espantando as indústrias" (PARMALAT AMEAÇA FECHAR, 2000, p. 12).

Um ano mais tarde a situação continuava difícil. Francisco Alvarenga, Diretor do Sindicato da Indústria de Laticínios, informava que "cerca de 36 empresas mineiras haviam encerrado suas atividades no estado, no rastro de grandes companhias como a Nestlé, a Itambé e a Cotochés, que decidiram investir em novas unidades em território goiano"(GUERRA FISCAL AMEAÇA, 2001, p. 8).

Nos setores de carne e couros, as conseqüências da guerra fiscal foram mais drásticas para Minas. Os estados de São Paulo, Bahia, Goiás, Mato Grosso do Sul, Espírito Santo e Ceará reduziram muito, ou mesmo eliminaram, as alíquotas do ICMS para esses setores, fortalecendo a competitividade de suas empresas e atraindo indústrias mineiras. Nos anos 90 foram fechados $65 \%$ dos abatedouros mineiros, principalmente depois de 1998, quando se acirrou a guerra fiscal. Entre 1996 e 2000 foram fechados 17 frigoríficos em Minas, enquanto em São Paulo foram abertos 11 e 6 em Goiás (FRIGORÍFICOS INSATISFEITOS, 2000).

O movimento comercial dos pecuaristas concentra-se atualmente na venda do gado vivo para 
outros estados. É uma curiosa regressão ao passado, pois a exportação do gado vivo era diagnosticada, desde o início do século XX, como fator de atraso da economia mineira. Tal diagnóstico resultou na montagem gradual de uma rede de abatedouros e frigoríficos para agregar valor à atividade, de modo a superar a relação "colonial" de mero fornecimento de matéria-prima para ser transformada em outros estados.

Em fins de 1999 o governo de Minas resolveu enfrentar o problema. Começou a estruturar o programa "Do boi ao sapato" para integrar a cadeia produtiva do setor de carne e couros. A proposta era de elevar o preço de referência do boi vivo para fins de ICMS. Restringindo-se a venda de bois para outros estados, seria aumentada a oferta interna de gado para os frigoríficos e indústrias de couro em Minas.

No entanto, a FAEMG (Federação da Agricultura do Estado de Minas Gerais) e os pecuaristas, que participavam das negociações para o lançamento do programa, retiraram o apoio. Consideraram que não lhes trazia benefícios, ao inviabilizar a venda de animais para São Paulo, o maior mercado consumidor do país. Apenas incentivaria maior sonegação no setor e os abates clandestinos ('DO BOI AO SAPATO', 2000, p. 14).

O projeto não avançou e a tensão fiscal continuou. Na mesma época, em abril de 2000, vários frigoríficos mineiros, insatisfeitos com a política tributária estadual para o setor, ameaçaram transferir-se para outros estados. Sob forte pressão, o governo estadual anunciou a redução da alíquota do ICMS sobre o abate e a industrialização da carne em Minas, de $2 \%$ e $3 \%$ respectivamente, para $0,1 \%$ em ambos os casos. Essa nova alíquota equiparava o custo fiscal dos frigoríficos mineiros aos de São Paulo e de Mato Grosso do Sul, seus principais concorrentes (SECRETÁRIO ANUNCIA REDUÇÃO, 2000, p. 3).

A redução do imposto, válida para os produtos bovinos e suínos, teria logo seus desdobramentos. O setor avícola reivindicou vantagem equivalente, uma vez que o ICMS cobrado desse ramo chegou a 7\% em Minas, inviabilizando a expansão dos abatedouros e prejudicando a implantação de novas fábricas. A Perdigão, por exemplo, havia desistido de se estabelecer em Minas e preferiu fazê-lo em Goiás. Também para esse setor o governo estadual cedeu, reduzindo o imposto a $0,1 \%$, alíquota equivalente à de outros estados (AVICULTURA
MINEIRA, 2000, p. 3).

Cada movimento nessa espécie de jogo de xadrez que é a guerra fiscal provoca efeitos imprevistos em alguma parte do sistema. Assim é que no início de 2001 noticiou-se que a indústria gaúcha de frango estava a perder espaço em seu próprio mercado. A participação dos frigoríficos locais nas vendas dentro do Rio Grande do Sul, que era de $44 \%$ em 1992, havia caído para $32 \%$ em 1999 e para 28\% em 2000. O Presidente da Associação Gaúcha de Avicultura, Paulo Vellinho, atribuiu a queda na participação ao custo dos insumos e também à guerra fiscal. Apontava a disparidade: enquanto no Rio Grande o ICMS para o setor é de 7\%, em Goiás é de 3\% e em Minas foi reduzido para $0,1 \%$, como vimos. "Em São Paulo, a tributação é idêntica à do Rio Grande do Sul, mas a flexibilização do crédito adotada pelo governo paulista encolhe o recolhimento para 2\%" (INDÚSTRIAS GAÚCHAS, 2001).

Para completar esse quadro descritivo, convém ressaltar o relativo êxito obtido pela Bahia e pelo Ceará em atrair empreendimentos no ramo de calçados. Parte da indústria de calçados do Rio Grande do Sul foi transferida para esses dois estados na década de 90. As vantagens auferidas foram extraordinárias: isenção quase total do ICMS, incentivos fiscais federais (via SUDENE), oferta de infra-estrutura e construção da fábrica, sem contar com o baixo custo dos salários e a frágil organização sindical dos trabalhadores locais. São experiências de industrialização que retratam notavelmente a heterogeneidade do Brasil - afinal a razão mais profunda da guerra fiscal.

\section{GUERRA E PAZ}

Do estudo aqui apresentado podem-se extrair algumas conclusões analíticas. A guerra fiscal tornou-se um dos fenômenos mais característicos da cena brasileira nos anos 90 em virtude de uma conjunção de fatores econômicos, institucionais e políticos. Foram muitos os estados envolvidos nos conflitos recentes, mas dada sua diversidade econômica e política, podem-se distinguir pelo menos dois tipos de clivagens entre eles. Os estados mais industrializados e de maior peso na federação têm competido por grandes projetos, geralmente de origem externa. Os demais estados têm disputado investimentos, basicamente de capital doméstico, em inúmeros setores produtivos. Por efeito dessa competição, observa-se o deslocamento de setores e empresas pelo território 
nacional, atrás de vantagens fiscais comparativas, além de diferenciais em custos como salários mais baixos. A ocorrência dessa movimentação de "empresas ciganas" depende do setor de atividade. É bastante viável em setores que requerem instalações e insumos disponíveis em qualquer lugar, como as indústrias de confecções, calçados, cerâmica e laticínios.

Além disso, a análise do teatro da guerra indica mudanças significativas no que diz respeito aos atores e aos seus padrões de atuação. Tendo em vista a tipologia de modelos de desenvolvimento regional apresentada no início deste artigo, vê-se que o modelo de desenvolvimento politizado por iniciativa interna estendeu-se para diversos estados, como o Paraná e a Bahia, sem falar de estados "emergentes", a exemplo de Goiás e de Mato Grosso do Sul, todos utilizando intensamente fórmulas de incentivo fiscal.

As conseqüências desse processo podem ser avaliadas sob duas perspectivas. Em primeiro lugar, há efeitos sistêmicos consideráveis. A guerra provoca tensões nas relações federativas e enfraquece o poder público em face de interesses privados. Há um aumento desmesurado do poder de barganha de investidores potenciais, sem benefícios compatíveis para o conjunto da economia e da sociedade. Isso é ainda mais grave na medida em que privilégios são concedidos a empresas cujos investimentos seriam feitos sem o montante de incentivos que lhes têm sido destinados.

Quanto aos efeitos locais, não se pode negligenciar o impacto desorganizador da guerra fiscal sobre a estrutura produtiva das regiões afetadas. Em que pesem os eventuais resultados positivos das políticas industriais implementadas no âmbito estadual, quando tais políticas têm como base o manejo de instrumentos fiscais o processo de expansão econômica resultante tende a ser artificial e pouco sustentável a longo prazo. Ele não passa de substituto precário de estratégias consistentes de desenvolvimento regional.

Não é tarefa fácil equacionar esse quadro de conflito, que se generalizou por grande parte do país. Contudo, considerando as vantagens e as desvantagens, é desejável que o ambiente de guerra fiscal seja substituído por um cenário mais pacífico. Mecanismos de regulação são necessários. Mas quais mecanismos? E em que grau de regulação?
Federações são arranjos relativamente instáveis, o que leva a dizer que a competição entre os estados brasileiros por oportunidades e meios de desenvolvimento não deve causar espécie. Essa competição pode ser construtiva, mas pode também revelar-se destrutiva, e é quanto a isso que formas de regulação devem ser encontradas e implementadas.

No período em que a União dispunha de recursos (financeiros e políticos) para dirigir o processo de desenvolvimento nacional, certo equilíbrio era viabilizado pela desconcentração de investimentos estatais, como contrapeso à concentração de investimentos privados no pólo econômico do país. Foi assim na época de Vargas, como também no governo Geisel, com o II Plano Nacional de Desenvolvimento.

A perda de capacidade de regulação do governo federal ocorreu em paralelo com o seu enfraquecimento econômico e financeiro. No entanto, isso não justifica uma atitude ausente do poder central sobre o que se passa com as unidades federadas. Até certo ponto, está em jogo a governabilidade da federação, o que deve interessar de perto à União. E isso diz respeito aos seus três poderes.

O poder Judiciário tem sido chamado a julgar ações diretas de inconstitucionalidade propostas por um estado contra lei de outro relativa à renúncia fiscal. Essa arbitragem, no entanto, é pontual e não assegura um ambiente de maior cooperação federativa.

O papel do Legislativo é de suma importância na construção e manutenção do pacto federativo. O Parlamento é o órgão que exprime, por excelência, a unidade na diversidade, o equilíbrio entre as partes e o todo. No sistema bicameral brasileiro o Senado Federal é a câmara de representação dos estados. Não seria de se esperar um papel mais ativo do Senado no ordenamento dos conflitos que afetam a federação?

Mas a tarefa é também do Executivo, pois o país é presidencialista. No âmbito do Executivo, o órgão encarregado da coordenação das relações fiscais interestaduais é o CONFAZ (Conselho de Política Fazendária), que se mostrou esvaziado e impotente diante da escalada da guerra fiscal na década de 90. É um órgão necessário, mas que precisa ser repensado. De fato, o governo federal tem adotado uma postura olímpica diante da guerra fiscal, que resulta, na prática, em estimulá-la. A 
opção de abandonar a implementação de políticas de coordenação inter-regional deve ser revista. É importante que se volte a pensar em políticas de desenvolvimento regional, naturalmente com metas e objetivos diferentes daqueles usados no passado.

Há amplo consenso quanto à conveniência de uma reforma tributária no Brasil. Entre seus objetivos estaria a superação do cenário de guerra fiscal ${ }^{2}$. A reforma tributária está em pauta desde a abortada reforma constitucional de 1993, mas a discussão quase não avançou, o que mostra a dificuldade de encaminhar os problemas atuais por essa rota. Por certo, o principal obstáculo a essa proposta reside no próprio modelo econômicofinanceiro em vigor, que tem na âncora fiscal a chave da estabilidade. $\mathrm{O}$ ajuste fiscal, afinal, tem funcionado como substituto precário de uma reforma tributária abrangente. A Lei de Responsabilidade Fiscal, em particular, introduziu fortes elementos de restrição ao desperdício de recursos públicos que decorre da guerra fiscal ${ }^{3}$.

Esse pode ser um passo significativo para se chegar ao objetivo mais amplo: um cenário construtivo no que tange ao pacto federativo.

Recebido em 3 de maio de 2002. Aprovado em 19 de maio de 2002.

2 Sobre a questão tributária no âmbito do sistema federativo brasileiro, v. Affonso e Silva (1995), e Prado e Cavalcanti (2000).

\footnotetext{
3 Sobre o contexto político do ajuste fiscal no Brasil, v. Loureiro (2001).
}

Otávio Soares Dulci (osd@dedalus.lcc.ufmg.br)é Doutor em Ciência Política pelo Instituto Universitário de Pesquisas do Rio de Janeiro (IUPERJ) e Professor do Departamento de Sociologia na Universidade Federal de Minas Gerais (UFMG).

\section{REFERÊNCIAS BIBLIOGRÁFICAS}

AFFONSO, R. B. A. \& SILVA, P. L. B. (orgs.). 1995. Reforma tributária e federação. São Paulo : FUNDAP/UNESP.

ARBIX, G. 2002. Políticas do desperdício e assimetria entre público e privado na indústria automobilística. Revista Brasileira de Ciências Sociais, Rio de Janeiro, v. 17, n. 48, p. 109-129, fev.

CANO, W. 1990. Raízes da concentração industrial em São Paulo. $3^{\mathrm{a}}$ ed. São Paulo : Hucitec.

DINIZ, C. C. 2000. A nova geografia econômica do Brasil. In : VELLOSO, J. P. R. (org.). Brasil 500 anos: futuro, presente, passado. Rio de Janeiro : José Olympio.
DULCI, O. S. 1999. Politica e recuperação econômica em Minas Gerais. Belo Horizonte : UFMG.

LOUREIRO, M. R. 2001. Instituições, política e ajuste fiscal : o Brasil em perspectiva comparada. Revista Brasileira de Ciências Sociais, Rio de Janeiro, v. 16, n. 47, p. 75-96, out.

PRADO, S. \& CAVALCANTI, C. E. G. 2000. $A$ guerra fiscal no Brasil. São Paulo : FUNDAP.

SILVA, P. L. B. 1997. A natureza do conflito federativo no Brasil. In : DINIZ, E. \& AZEVEDO, S. (orgs.). Reforma do Estado e democracia no Brasil. Brasília : UnB.

\section{OUTRAS FONTES}

Avicultura mineira mais competitiva com a redução do ICMS. Indústria de Minas, Belo Horizonte, ago.2000.

Briga por incentivos na Lei de Informática. Gazeta Mercantil, São Paulo, 31.mar.2000.
Covas decide revogar benefício fiscal. O Tempo, Belo Horizonte, 07.ago.1999.

Covas quer derrubar isenções à Ford. Jornal do Brasil, Rio de Janeiro, 22.fev.2000. 
'Do boi ao sapato' pode se tornar inviável. $O$ Tempo, Belo Horizonte, 03.abr.2000.

Frigoríficos insatisfeitos ameaçam deixar Minas Gerais. O Tempo, Belo Horizonte, 19.abr.2000.

Guerra fiscal ameaça Minas. Estado de Minas, Belo Horizonte, 09.jul.2001.

Incentivo a montadora valerá até 2010. Folha de S. Paulo, 21.jul.1999.

Indústrias gaúchas perdem terreno. Gazeta Mercantil, São Paulo, 09.fev.2001.

Lei de Informática atrai investimentos ao País.
Gazeta Mercantil, São Paulo, 12.jan.2001.

Minas vai ao Supremo contra São Paulo. O Tempo, Belo Horizonte, 05.ago.1999.

Parmalat ameaça fechar fábrica de Itamonte. Estado de Minas, Belo Horizonte, 30.dez.2000.

São Paulo investirá $\mathrm{R} \$ 136,9$ mi na Embraer em Gavião Peixoto. Folha de S. Paulo, 29.jun.2000.

Secretário anuncia redução de ICMS da carne. Estado de Minas, Belo Horizonte, 04.maio.2000. 